\title{
Providing opportunistic immunisations for at-risk inpatients in a tertiary paediatric hospital
}

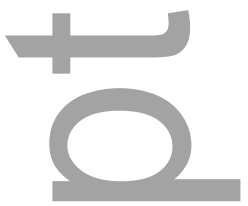

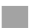

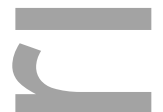

Sonja Elia, MAdvNursPrac, RN

Nurse Manager, Immunisation Service, Department of General Medicine, Royal Children's Hospital, 50 Flemington Rd, Parkville, Victoria, 3052 Australia

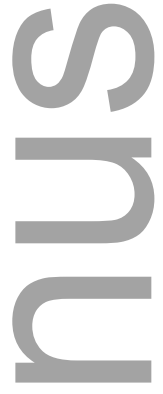

Dr Kirsten Perrett, MBBS, FRACP, PhD

Immunisation Paediatrician, Vaccine and Immunisation Research Group (VIRGo), Murdoch Children's Research, Institute and Melbourne School of Population and Global Health, The

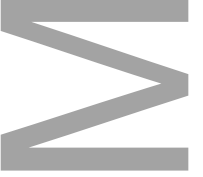
University of Melbourne, Victoria, 3010 Australia.

Dr Fiona Newall PhD, MN, B.Sci(Nsg), RN

Director, Nursing Research Department, Royal Children's Hospital, 50 Flemington Rd, Parkville, Victoria, 3052
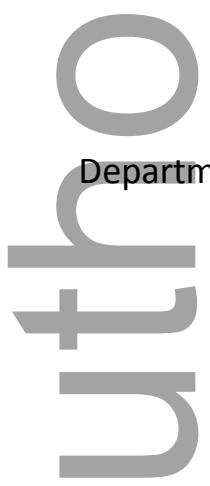

This is the author manuscript accepted for publication and has undergone full peer review but has not been through the copyediting, typesetting, pagination and proofreading process, which may lead to differences between this version and the Version of Record. Please cite this article as doi: $10.1111 /$ jspn. 12167.

This article is protected by copyright. All rights reserved. 
IMMUNISATION OF INPATIENTS

\section{Declarations}

Competing interests The authors report no actual or potential conflicts of interests.
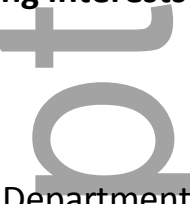

Funding Department of Health and Human Services, Victoria - Immunisation Section funded the clinical work undertaken.

Contributorship Main Author - SE. sonja.elia@rch.org.au Co-authors - KP and FN

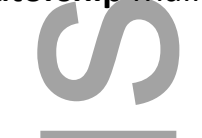

Acknowledgements The authors would like to acknowledge the contributions of the ward Nurse Coordinators as well as the Immunisation Service nursing staff who participated in this clinical work.

Abstract

Attaining high immunisation coverage rates for children with medical conditions is vital. The Royal Children's Hospital (RCH) Immunisation service has the opportunity to check each inpatient's immunisation status and provide opportunistic vaccines and/or bring the Australian Childhood Immunisation Register (ACIR) up-to-date. This paper highlights that during admission, one quarter of children were not up to date with routine scheduled immunisations and $42 \%$ of those inpatients due or overdue for immunisation, were vaccinated. The model of establishing routine checking of immunisation records, and reminding hospital staff about immunisation can result in improvements in vaccination coverage.

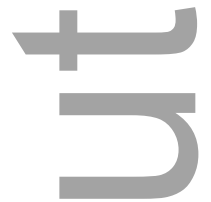

Health care providers have a responsibility to check immunisation status and offer vaccines when necessary, however often there are missed opportunities to immunise. This article demonstrates

This article is protected by copyright. All rights reserved. 
IMMUNISATION OF INPATIENTS

that having a dedicated Immunisation service, a partnership with a relevant government agency and effective collaboration with inpatient clinical teams, opportunistic immunisation can be achievable for inpatients.

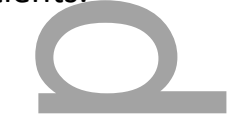

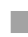

Search terms: immunisation, children, coverage, hospital

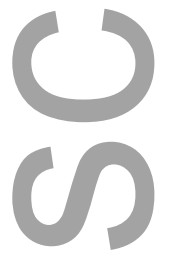

Immunisation is one of the most efficient and cost-effective public health interventions (NHMRC, 2013). In Australia, the overall national immunisation coverage target is $95 \%$ and this is measured across three data collection points; one year, two years and five years of age. In 2016, $92.7 \%$ of children by 5 years of age had received all of the routine vaccines on the National Immunisation Program (NIP) schedule. Coverage in Aboriginal and Torres Strait Islander children is slightly higher at 5 years of age $(94.3 \%)$ but is lower in the earlier age points, suggesting issues with timeliness. This data is recorded using the Australian Childhood Immunisation Register (ACIR). From 30 September 2016, the register has broadened to a 'whole of life' register to capture all vaccines administered throughout a person's life (Australian Government, 2016). In addition, the federal government passed the 'No jab, no pay' legislation, affecting family assistance payments of the non-immunised, while the state government passed the No jab, no play' legislation which has implications on child care and kindergarten enrolment for children not up to date with immunisation. Therefore, every health service presentation should be considered an opportunity to ensure 
IMMUNISATION OF INPATIENTS

that children are immunised (Berling et al. 2012). This discussion paper will describe an innovation in clinical practice.

\section{Children at increased risk}

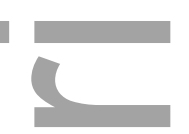

Children in special risk groups (see table 1) (NHMRC, 2013) are deemed a high risk population and this intensifies the threat of morbidity and mortality from vaccine preventable diseases (Hjuler et al. 2008). Whilst this ought to increase the impetus on health professionals to ensure that immunisation status is up to date, as well as identify that additional special risk vaccines may be required, this is often not the case. Ressler et al. (2008) reported that children presenting to a health service have lower immunisation uptake rates than the general population. Reasons for this have been attributed to a lack of formal ward-based policies for opportunistic immunisation, poor documentation of immunisation plans and the need for education of paediatric ward staff.

Financial and human resource factors within health care organisations have been identified as being major contributors to challenges in recalling and/or reminding families of the importance of immunisation, especially in children with underlying medical conditions (Pereira et al. 2012). It was also identified that a lack of staff confidence in immunisationrelated data, as well as limited prioritisation of immunisation status by physicians were additional barriers towards the implementation of immunisation reminder/recall systems. Given the ever-increasing complexity of children presenting to tertiary and secondary health 
IMMUNISATION OF INPATIENTS

care services, it is of utmost importance that they receive due or overdue immunisations in accordance with the NIP schedule.

\section{Model of opportunistic immunisation}

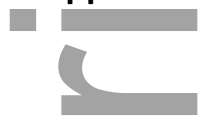

The Royal Children's Hospital (RCH) is the major specialist paediatric hospital in Victoria providing a full range of clinical services, tertiary care and health promotion and prevention programs for children and young people. The Immunisation service at the $\mathrm{RCH}$ was established in the mid-1990s as a co-funded partnership with the Department of Health - Immunisation section, where the key strategic aim was to improve opportunistic vaccination. The opportunistic model has been shown to improve immunisation coverage and re-engage families with primary care services, by providing a plan for catch-up immunisations (Shingler et al. 2012). Therefore, an immunisation nurse was mobilised to visit wards and outpatient areas to provide immunisations. In 2001, the Immunisation service was further developed to include a drop-in centre, a telephone advice line and a specialist immunisation outpatient clinic. The $\mathrm{RCH}$ Immunisation team operates with the philosophy that everybody who walks through the door of the hospital should be up-to-date with their immunisations, including children, siblings, parents and visitors.

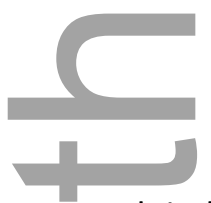

Research indicates that more than half of direct line staff consider it inappropriate for children to be vaccinated prior to discharge from hospital, potentially due to insufficient time and lack of immunisation knowledge (Walton, Elliman \& Bedford, 2007). Unfortunately, this is still the This article is protected by copyright. All rights reserved. 
IMMUNISATION OF INPATIENTS

case in recent times (Tafuri et al. 2014). The Immunisation service enables RCH direct care staff to refer children to experts in the field of immunisation and this has steadily increased the service activity of the Immunisation drop-in centre. Children can simply walk-in to the centre for immunisation, with no appointment necessary, maximing the opportunistic nature of the service. Whilst vitally important, however, with the steady increase in the drop-in centre activities, this has meant that the most vulnerable populations - the inpatients - were missing out on opportunistic immunisations. The nurses were becoming increasingly busy in the centre and no longer able to visit the wards. An analysis of the immunisation status for hospital inpatients, aged between 6 weeks to 7 years, carried out from 21 September 2011 to 28 March 2012, identified that 30\% (134/452) were due or overdue NIP immunisations, compared to the state-wide average of $10 \%$ in the same age cohort (Wall et al. 2012). Of the due or overdue children, ACIR records were checked one month after discharge and only $26 \%$ (35/134) had been immunised and brought up to date.

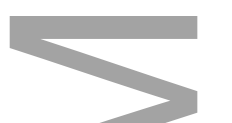

The ACIR, a national register that records details of immunisations is a vital component in identifying due or overdue immunisation status (Hull, Deeks \& McIntyre, 2009). The Royal Children's Hospital $(\mathrm{RCH})$ Immunisation service is able to check immunisation status using the ACIR, facilitating the provision of opportunistic vaccines and/or bringing a child's ACIR record up-to-date.

\section{Opportunistic immunisation: a pilot program}

Following the initial analysis in 2012, an increase in funding was secured via the Department of Health, to support the creation of a pilot program to identify inpatients requiring opportunistic immunisation and contribute to accurate data capture within the ACIR. The funding provided one full-time equivalent administrative staff, an extra one full-time equivalent nursing staff and one extra This article is protected by copyright. All rights reserved. 
IMMUNISATION OF INPATIENTS

medical session. The pilot program (1 September 2013 to 31 January 2014) involved ongoing consultation with key stakeholders including the hospital executive, ward staff and pharmacy, in order to refine and streamline the process of tracking and immunising this vulnerable cohort of children. During the initial analysis, the Immunisation team conducted a daily search of all ward inpatient lists to find children aged between six weeks and seven years. The list of patients was then cross-referenced with the ACIR, to determine each child's immunisation status, including their need for special risk vaccines. The national due and overdue rules for childhood immunisation, according to ACIR were applied. Children were considered "overdue" for immunisations, if they were 30 days or more overdue for the age-appropriate vaccines at the date of admission to hospital; they were "due" for immunisations, if the immunisation due date was less than 30 days prior. The recognition of overdue patients is now more critical due to the 'No jab, no pay' legislation, as their families may be subjected to financial disadvantage.

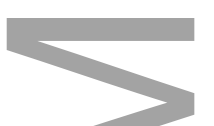

This was a time consuming and potentially flawed system, due to the possibilty of overlooking some children in this broad and extensive list. Engagement with the information technology department enabled the development of an enhanced filtering system which supported immediate identification of a daily list of targeted children. Using the same methodology as the initial analysis, this list was cross-referenced with the ACIR. Once children were identified as due or overdue, the Immunisation service nurses liaised with the ward based nurse coordinators regarding administration of immunisations and/or the need for parental consultation related to immunisation. If vaccinating the child immediately was contraindicated, the Immunisation team developed an immunisation plan to support immunisation at a later date, either within $\mathrm{RCH}$ or via the child's general practitioner (GP) or other local immunisation provider. The Immunisation service reviewed 
IMMUNISATION OF INPATIENTS

these children, by checking the ACIR one month post-discharge to determine whether immunisations were completed and that their ACIR status was up-to-date. If the child was not upto-date, there would be the potential to flag them again in a subsequent admission, otherwise the family would be sent the usual ACIR reminder letter of overdue immunisation status.

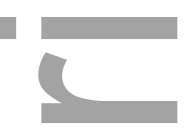

Through this pilot program, the Immunisation service identified that $25 \%(831 / 3,374)$ of the hospital's inpatients were due or overdue for vaccines. Of the due or overdue inpatients, approximately $42 \%$ (352/831) were brought up-to-date with their scheduled immunisations. Of those vaccinated, $51 \%$ (179/352) children were brought up-to-date during their admission to RCH, with the remainder $49 \%$ (173/352) received their scheduled immunisations within one month post discharge. Of those vaccinated following discharge, most [70\% (121/173)] received vaccines at the GP, $29 \%(50 / 173)$ received them at council immunisation sessions and $1 \%(2 / 173)$ with other immunisation providers.

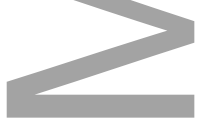

The $58 \%$ (479/831) of children who were not opportunistically immunised, immunisation status was checked 2 years later using the ACIR. Of these children, $71 \%$ (340/479) were up to date, $26 \%(123 / 479)$ were still overdue and $3 \%(16 / 479)$ deceased. These results suggest that in this cohort, sustaining ideal rates of immunisation appears to be more challenging than immunisation rates reported on a national level. This reality remains present even after the intervention of an Immunisation service during an acute hospital admission. This is of significant concern given that timeliness of immunisation is critical to protect both the individual and the population (Luman et al. 2002). Many factors may contribute to this timeliness of immunisation amongst inpatients and This article is protected by copyright. All rights reserved. 
IMMUNISATION OF INPATIENTS

future qualitative surveys of both health professionals and parents may be helpful in understanding what these are.

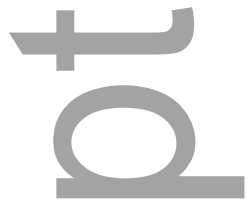

Key to the success of our pilot project was the close liaison between the Immunisation service staff and ward-based nursing staff. Ward staff were heavily involved in talking to the identified families about immunisations, and providing the required immunisation. Monthly meetings are held to support this collaboration. The Immunisation service staff also conduct education sessions and provide support and training for ward nurses and pharmacists regarding childhood immunisation and vaccine storage. To support clinical staff, the Immunisation service staff further developed existing internet resources. These included a WebApp, with built-in alerts for children with certain conditions as well as a new clinical guideline, the 'Immunisation of inpatients'. These resources are available to all RCH staff and external immunisation providers and there have been over 6,000 page views in the first 12 months.

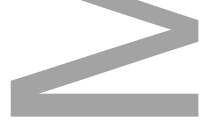

\section{The future and funding}

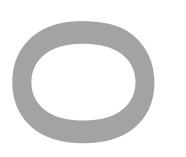

Whilst this program has been effective in delivering opportunistic immunisation within a tertiary paediatric centre, the future of an electronic health record (EHR) at the $\mathrm{RCH}$ has the ability to track children in need of vaccines, identify children whose immunisations are delayed and promote interdisciplinary communication amongst personnel involved in the immunisation process (Au et al.2010). With the ability to record a patient's immunisation history as well as identify due or 
IMMUNISATION OF INPATIENTS

overdue vaccines into the problem list, the incorporation of an EHR at RCH linked with the ACIR, will provide faster, easier access to immunisation status and will facilitate improved opportunistic immunisation of inpatients.

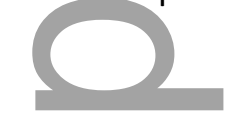

$\square$<smiles>C1C2CC1C2</smiles>

The net result of these efforts during the pilot program was an increase in immunisation uptake to some of the most vulnerable populations (due or overdue NIP vaccines), with $26 \%$ of inpatients receiving catch-up immunisations in $2011 / 12$ compared to $42 \%$ in $2013 / 14$. This is a far better rate than previously reported. In 2009, an audit in a New Zealand hospital found only $4 \%$ of under immunised children received catch-up immunisation whilst on the ward (Gilbert \& Wrigley, 2009). Similarly a study by Jose, Gilles \& Kelley (2016) of admitted children in a regional hospital in Western Australia, demonstrated $8 \%$ of children were immunised whilst in hospital. We postulate that our model of establishing routine checking of immunisation records, and reminding hospital staff about immunisations due or overdue may be the difference.

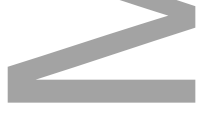

In summary, this discussion paper describes how opportunistic immunisation within a tertiary paediatric centre can be successfully enabled through partnership with a relevant government agency, effective collaboration with inpatient clinical teams and the development of an appropriate IT infrastructure. Our approach to opportunistic immunisation for at-risk inpatients should be of broad interest to clinicians working in immunisation, especially in a hospital setting.

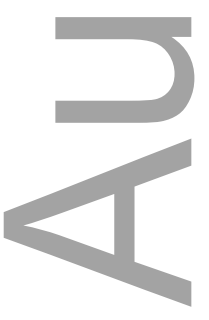

This article is protected by copyright. All rights reserved. 
IMMUNISATION OF INPATIENTS

How might this information affect nursing practice?

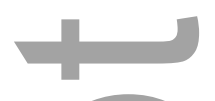

Nurses play a key role in increasing immunisation rates, not only by organising and delivering immunisation but also through providing information about vaccines. This model of opportunistic immunisation during hospitalisation enables nurses to extend their organisational role to take a more proactive approach to providing vaccines. Whilst it may not be initially feasible to open a dedicated immunisation centre, having enthusiastic nurse immunisers within the hospital environment can facilitate screening of inpatients immunisation history and then addressing potential barriers to promoting opportunistic immunisation practices.

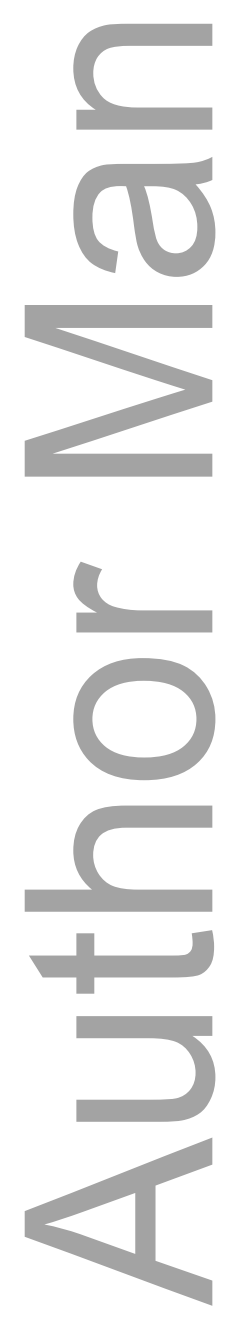

This article is protected by copyright. All rights reserved. 
IMMUNISATION OF INPATIENTS

References

National Health and Medical Research Council (NHMRC). (2013). Australian Immunisation Handbook, $\left(10^{\text {th }}\right.$ ed.). Canberra: National Capital Press.

Australian Government Department of Health. (2016). Fact sheet - Immunisation registers

expansion. Retrieved 12 June 2016 from

http://www.immunise.health.gov.au/internet/immunise/publishing.nsf/Content/523BCE12C8

BCA187CA257EE700118E99/\$FFile/Factsheet-\%20Immunisation-Registers-Expansion-

23102015.pdf

Berling, I, Stephenson, J, Cashman, P, Loten, C, Butler, M \& Durrheim, D. (2012). Opportunistic childhood vaccinations in emergency - Are we really missing anyone? Australasian Emergency Nursing Journal, 15(1), 37-44. doi:10.1016/j.aenj.2011.12.002

Hjuler, T, Wohlfahrt, J, Staum Kaltoft, M, Koch, A, Biggar, R.J \& Melbye M. (2008). Risks of invasive pneumococcal disease in children with underlying chronic diseases. Pediatrics, 122(1):e26-32. doi:10.1542/peds.2007-1510.

Ressler, K.A, Orr, K, Bowdler, S, Grove, S, Best, P \& Ferson M.J. (2008). Opportunistic immunisation of infants admitted to hospital: Are we doing enough?. Journal of Paediatrics and Child Health, 44(6), 317-320. doi: 10.1111/j.1440-1754.2007.01268.x.

Pereira, J.A, Quach, S, Heidebrecht, C.L, Quan, S.D, Kolbe, F, Finkelstein, M \& Kwong, J.C. (2012). Barriers to the use of reminder/recall interventions for immunizations: a systematic review. Bio Med Central Medical Informatics and Decision Making,12:145. doi: 10.1186/1472-6947$12-145$

This article is protected by copyright. All rights reserved. 
IMMUNISATION OF INPATIENTS

Shingler, S, Hunter, K, Romano, A \& Graham D. (2012). Opportunities taken: The need for and effectiveness of secondary care opportunistic immunisation. Journal of Paediatrics and Child Health, 48(3), 242-46.

Walton, S, Elliman, D \& Bedford, H. (2007). Missed opportunities to vaccinate children admitted to a paediatric tertiary hospital. Archives of Disease in Children, 92(7), 620-22.

Tafuri, S, Gallone, M.S, Cappelli, M.G, Martinelli, D, Prato, R \& Germinario, C. (2014). Addressing the anti-vaccination movement and the role of HCWs. Vaccine, 32(38), 4860-65.

Wall, K, Crawford, N, Elia, J, McGuire, R, Addison, M, Lewis, G, Quinn, J, Royle, J \& Dallinger, M. Catch up immunisations for hospital inpatients less than 8 years of age at a tertiary paediatric hospital. Poster session presented at: Public Health Association of Australia, $13^{\text {th }}$ National Immunisation Conference; 2012 Jun 19-21; Darwin, Australia.

Hull, B.P, Deeks, S.L \& Mclntyre, P.B. (2009). The Australian Childhood Immunisation Register - A model for universal immunisation registers? Vaccine, 27(37), $5054-60$.

Luman, E.T, McCauley, M.M, Stokley, S, Chu, S.Y \& Pickering, L.K. (2002). Timeliness of Childhood Immunizations. Pediatrics, 110(5), 935-39.

Au, L, Oster, A, Yeh, G.H, Magno, J \& Paek H.M. (2010). Utilizing an Electronic Health Record System to Improve Immunisation Coverage in Children. Applied Clinical Informatics, 1(3), 221-231.

Gilbert, R \& Wrigley, K. (2009). Opportunistic immunisation of paediatric inpatients at Rotarua Hospital: audit and discussion. The New Zealand Medical Journal, 122(1298), 25-30.

This article is protected by copyright. All rights reserved. 
IMMUNISATION OF INPATIENTS

Jose, D, Gilles, M \& Kelley S.J. (2016). Audit of opportunistic immunisation of paediatric inpatients in rural Western Australia. Australian and New Zealand Journal of Public Health, 40(1), 97-98.

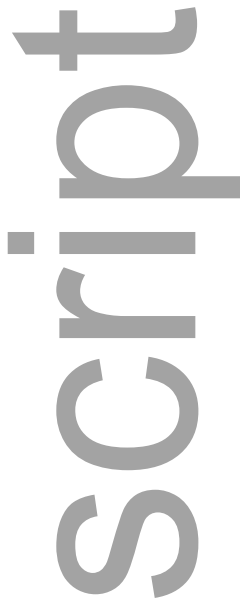

Table 1: Groups with special vaccination requirements

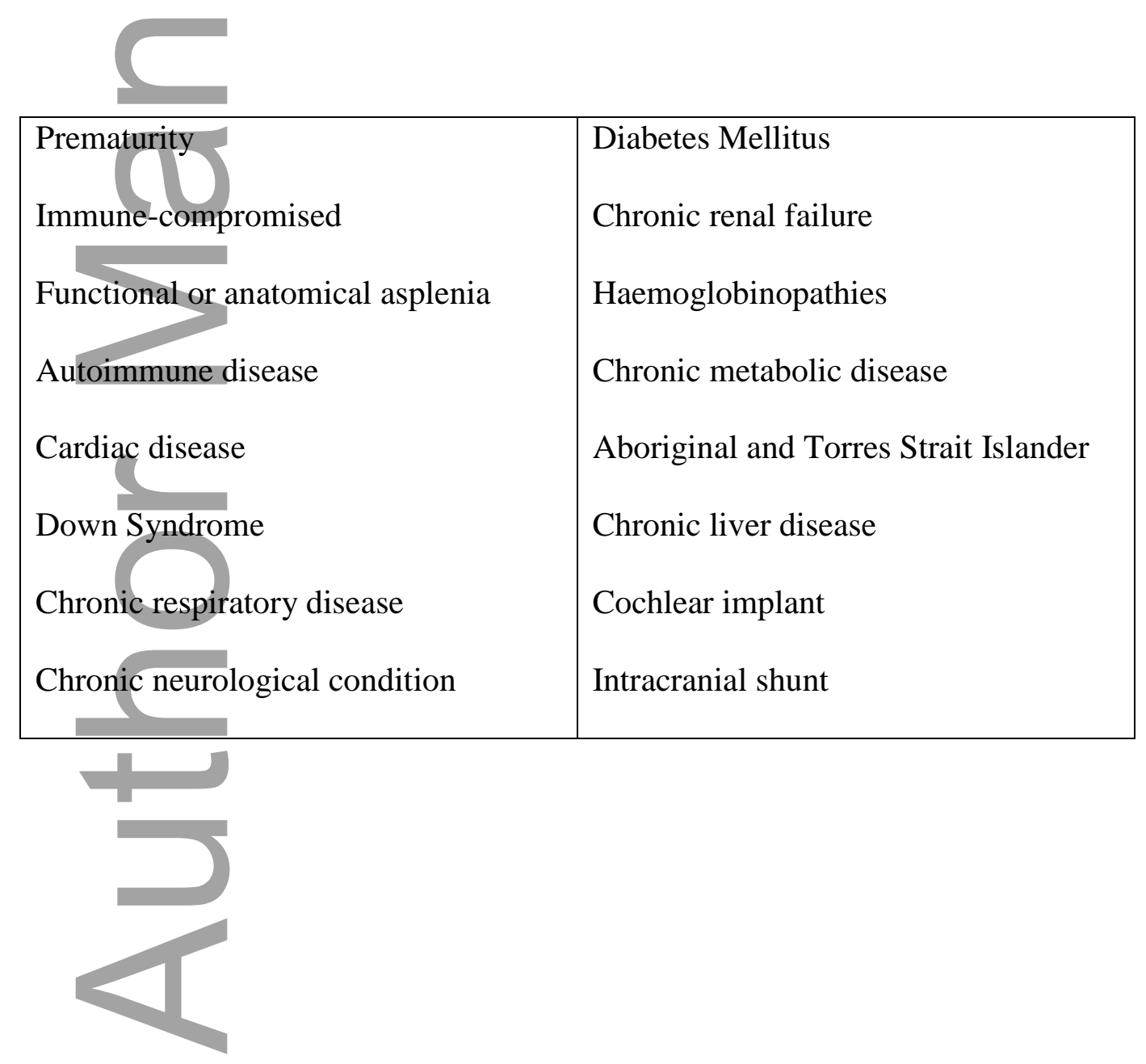

This article is protected by copyright. All rights reserved. 


\section{University Library}

\section{- M M N E R VA A gateway to Melbourne's research publications}

Minerva Access is the Institutional Repository of The University of Melbourne

Author/s:

Elia, S;Perrett, K;Newall, F

Title:

Providing opportunistic immunisations for at-risk inpatients in a tertiary paediatric hospital

Date:

2017-01-01

Citation:

Elia, S., Perrett, K. \& Newall, F. (2017). Providing opportunistic immunisations for at-risk inpatients in a tertiary paediatric hospital. JOURNAL FOR SPECIALISTS IN PEDIATRIC NURSING, 22 (1), https://doi.org/10.1111/jspn.12167.

Persistent Link:

http://hdl.handle.net/11343/292282 